\title{
AVISO
}

Por no disponer de los correspondientes originales informáticos, la maquetación de este artículo difiere de la del publicado en papel. Por lo demás, los contenidos no han sufrido ninguna alteración.

Artículo publicado en el fascículo $1^{\circ}$ del tomo LXV (1997) de EMERITA, pp. 1-16

Autor: Esteban Calderón Dorda

\section{LOS TÓPICOS ERÓTICOS EN LA ELEGÍA HELENÍSTICA *}

Love appears to be the favourite topic of elegy in the Hellenistic period. Among the preserved fragments, we find a detailed description and analysis of this topic regarding its nature, symptoms and consequences. All this literary work is carried out by the Hellenistic and PreHellenistic poetics, using perfectly codified topics.

La elegía de época helenística, como el resto de la poesía alejandrina, es el resultado de la convulsionada herencia social y política de Alejandro Magno, que dejó a la Helenidad fragmentada en una serie de reinos helenísticos cuyos soberanos detentaban un poder absoluto; consecuencia de lo cual sería que los ciudadanos, desvinculados ya del concepto de $\pi$ ó $\lambda 1 \varsigma$, se desinteresaron de los asuntos públicos bajo esta nueva forma de monarquía ${ }^{1}$. El derrumbamiento del concepto tradicional de $\pi$ ó $\lambda ı \varsigma$ tuvo como consecuencias la aparición del individuo cosmopolita, el florecimiento de una clase media de comerciantes y artesanos acomodados, la creación de bibliotecas y núcleos académicos, un panorama, en definitiva, bien diferente de lo ofrecido en los siglos anteriores. También los gustos estéticos y literarios sufrirán una evolución. Es una sociedad la helenística alejada de los ideales y heroísmos, instalada en lo material y reacia a toda rebeldía que comporte peligros y asperezas, y cuyo cosmopolitismo se complace con ingredientes tan excitantes como las leyendas, las aventuras, los viajes y las costumbres exóticas, pero sobre todos ellos prima el amor.

En este género renovado que será la elegía ${ }^{2}$, se perfila como tema favori-

* El presente artículo recoge, en buena medida, el texto de la conferencia pronunciada por el autor en la Universidad Internacional «Menéndez y Pelayo» bajo el título «Amor y desamor en la elegía helenística», dentro del curso «El amor en la poesía griega y latina» (Santander, 8-12 de agosto de 1994).

1 E. Calderón, «La elegía de época helenística», Tempus 7, 1994, pp. 5-32 (en p. 5).

2 Citamos los textos por las obras de I.U. Powell, Collectanea Alexandrina, Oxford 1925 (= CA) y de H. Lloyd-Jones y P. Parsons,Supplementum Hellenisticum, Berlín-Nueva York $1983(=S H)$. 
to, aunque no exclusivo, el amor. La concepción de una colección de elegías inspiradas todas ellas por una mujer, cuyo nombre constituye el título es típicamente helenística: Hermesianacte de Colofón compuso una colección que llevaba por título Leontion y Filetas de Cos parece ser que hizo lo propio con una colección intitulada Bítide ${ }^{3}$; sin embargo, esta idea, que tan bien toma cuerpo en la poesía alejandrina, es anterior, como nos recuerdan la Nano de

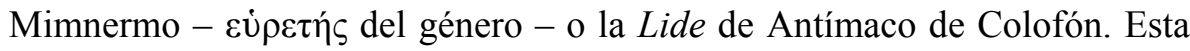
costumbre fue imitada por la elegía latina, y así encontramos a Propercio, que cantó a Cintia, o a Tibulo, que hizo lo propio con Delia, entre otros.

En los restos que nos quedan de la elegía de época helenística se analiza y describe de una manera bastante pormenorizada la naturaleza, los síntomas y las consecuencias del amor. Muchas de las historias que los poetas helenísticos escogieron para transformarlas en elegías, contenían como principal ingrediente el elemento amoroso. Los tópicos y elementos eróticos que encontramos codificados en la poesía helenística ${ }^{4}$, en general, y en la elegía, en particular, no son un fenómeno surgido de la nada, sino el resultado de un proceso que tiene sus inicios en las poesías de Mimnermo o de Safo ${ }^{5}$. Este proceso tiene su apogeo en la época que nos ocupa, y su continuación en la literatura latina. De aquí pasará a la literatura medieval y a la posteridad.

Junto a estos fragmentos de Hermesianacte, Fanocles, Alejandro el Etolo, Calímaco, etc., tendremos en cuenta los resúmenes en prosa que realizó el también elegíaco Partenio de Nicea. Los argumentos eróticos que Partenio ofrece a su amigo, el romano Cornelio Galo, para que los utilice, según su criterio, en la composición de elegías y poemas épicos, son el resultado de la literaturización de una serie de mitos y leyendas que han perdido su contexto original. Esta literaturización puede explicar, en parte, la objetividad de la

3 Hermesian., CA 7, 75 ss. cf. L. Alfonsi, «La poesia amorosa di Fileta», Aegyptus 22, 1943, pp. 160-168. Sobre la poesía amorosa de Filetas: P. D'Angelo Capra, «Fileta poeta d'amore?», AFLC 16, 1949, pp. 81.143. En general, puede verse: C. Del Grande, «Elegia alessandrina e sviluppo novellistico», en Miscellanea di Studi Alessandrini in mem. di A. Rostagni, Turín, 1963, pp. 225-233.

4 La codificación de los tópicos eróticos en la poesía helenística ha sido recogida por A. Buchholz, Zur Darstellung des Pathos der Liebe in der hellenistischen Dichtung, Diss. Friburgo 1954.

5 cf. G. Giangrande, «Carácter de la poesía helenística», Ant. Est. Filol. 7, 1984, pp. 3362 (en p. 42 s.).

EMERITA. Revista de Lingüística y Filología Clásica (EM) - LXV 1, 1997, pp. 1-16 
elegía erótica griega ${ }^{6}$. Las historias eróticas legendarias narradas por Partenio de Nicea han servido fundamentalmente como $\pi \alpha \rho \alpha \delta \varepsilon i \gamma \mu \alpha \tau \alpha$ del contenido de las elegías de la época. La elegía helenística contaba, además, con el precedente de Antímaco de Colofón que, según nos cuenta Plutarco (Cons. ad Apoll. 9), tras la muerte de su esposa Lide, compuso una colección de elegías con el título de Lide con el fin de mitigar su dolor; en estas elegías narraba una tras otra las desventuras amorosas de los héroes. Asimismo, los soliloquios sentimentales también tenían su lugar en historias como la recogida en la elegía de Calímaco Aconcio y Cidipe ${ }^{7}$.

Los elegíacos helenísticos expresaban su dolor desde el mito, histórico o legendario, tomando de éste la parte más patética, siguiendo las indicaciones del iniciador de la elegía alejandrina, Filetas de Cos (CA 10, 3-4):

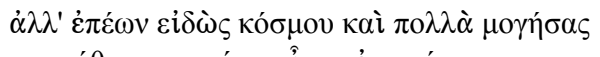

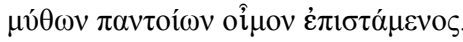

La elegía, por tanto, tiende a presentar los conflictos emocionales humanos dentro de una dimensión mítica. Con todo, las historias de amor incluidas por los poetas elegíacos helenísticos en sus composiciones no eran un mero adorno, sino que, por lo general, respondían al carácter probatorio del argumento, es decir, constituían un aítıov - en el sentido calimaqueo del término - que venía a demostrar las afirmaciones del poeta. Tal vez el ejemplo más representativo sea el fragmento de Fanocles $(C A 1)$ que presenta dos

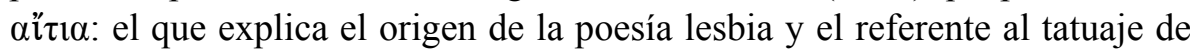
las mujeres tracias.

Para los poetas eróticos griegos prima sobre todas las cosas el deseo por la belleza: los protagonistas siempre son personajes de gran hermosura ${ }^{8}$. Ca-

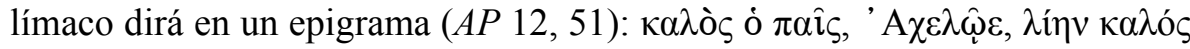
..., y Aconcio, en la elegía Aconcio y Cidipe, desea que todos los árboles del

6 Cf. C. Miralles, «Grècia i Roma: Originalitat de l'elegia eròtica llatina», Homenatge a J. Alsina, Barcelona, 1969, pp. 149-163 (en p. 157 s.).

7 Algunos tópicos eróticos han sido recogidos por M. Sánchez Ortiz de Landaluce, «Acontio y Cidipa y la novela griega: un nuevo análisis de motivos literarios recurrentes», Actas del VIII Congreso Español de Estudios Clásicos, II, Madrid, 1994, pp. 423-428.

8 En los $\dot{\varepsilon} \omega \tau \imath \kappa \grave{\alpha} \pi \alpha \theta \eta \dot{\mu} \mu \tau \alpha$ de Partenio de Nicea se pueden encontrar expresiones

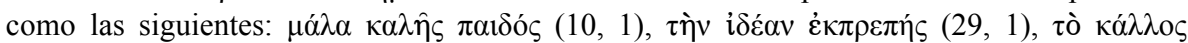

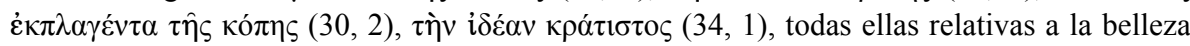
del héroe o heroína.

EMERITA. Revista de Lingüística y Filología Clásica (EM) - LXV 1, 1997, pp. 1-16 


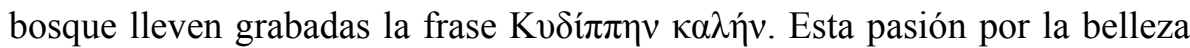
puede plantear situaciones de lo más escabroso. Tal es el caso que nos narra Partenio (Narr. Am. 31), según el cual Dimetes desposó a su sobrina Evópide, pero al descubrir el padre de la muchacha que ella mantenía relaciones

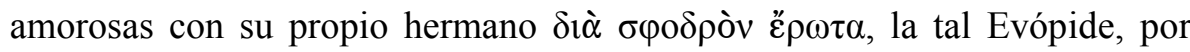
miedo a la reacción paterna y por vergüenza, decidió ahorcarse. Algún tiempo después, Dimetes se encontró en la playa el cadáver de una mujer arrojado por las olas. Resultó que era una mujer $\mu \alpha \lambda^{\lambda} \alpha \kappa \alpha \lambda \eta ́$, por lo que, inducido por el deseo, no tuvo reparos en acostarse con ella, hasta que comenzó a des-

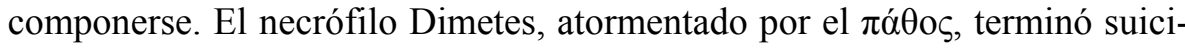
dándose ${ }^{9}$.

Esta idea básica consistente en buscar sobre todo la belleza, no la contradicen los elegíacos helenísticos. Según esto, el acto de enamorarse no era un proceso lento, sino algo instantáneo ${ }^{10}$. Este es un aspecto fundamental: la «instantaneidad» del enamoramiento; el enamorado es alcanzado por la flecha de Eros. Meleagro confiesa $(A P 5,198)$ que Eros le ha atormentado de tal manera que todos los dardos del dios están clavados en él. Por esta razón

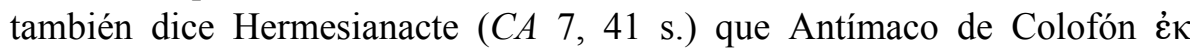

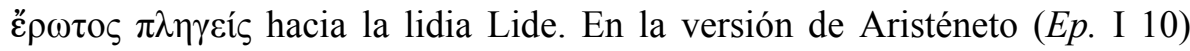
correspondiente al fr. 70 Pfeiffer de la famosa elegía de Calímaco Aconcio y

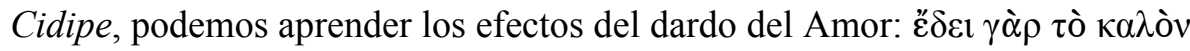

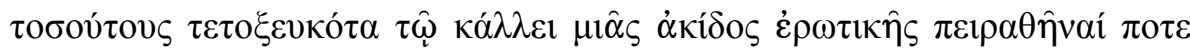

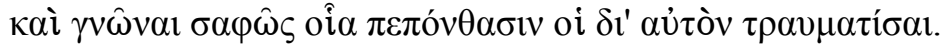

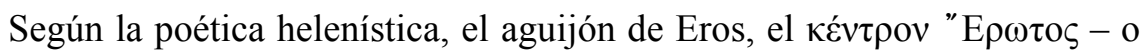

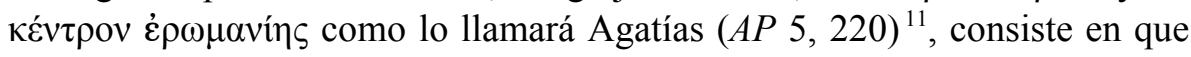

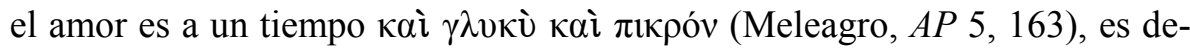

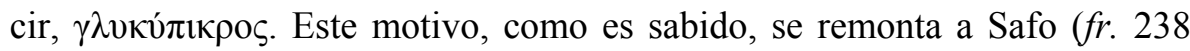
Page). También en Eurípides (Hipp. 348) encontramos el motivo del Amor

9 La belleza es considerada en un epigrama atribuido a Platón ( $A P \mathrm{~V} 79)$ como algo

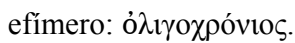

10 Este $\tau$ ó $\pi$ o $\varsigma$ del amor a primera vista - y otros aspectos - ha sido estudiado en Apolonio de Rodas en relación a Medea por M. Fusillo, «Apollonio Rodio», en Lo spazio letterario della Grecia antica. I. La produzione e la circolazione del testo. II. L' Ellenismo, Roma, 1993, pp. 107-143 (en pp. 120-127).

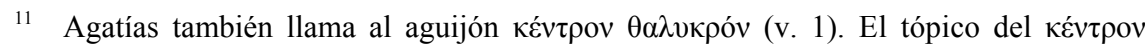

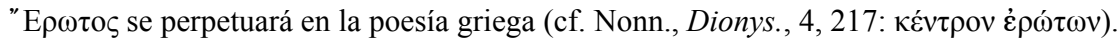

EMERITA. Revista de Lingüística y Filología Clásica (EM) - LXV 1, 1997, pp. 1-16 


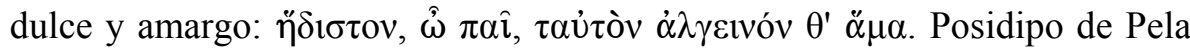

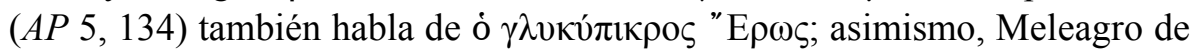
Gádara $(A P 12,109)$ sintetiza este programa en un interesante epigrama:

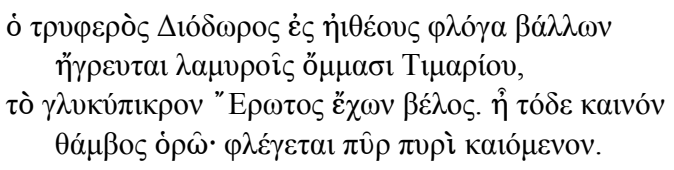

Esta naturaleza $\gamma \lambda v \kappa v ́ \pi \iota \kappa \rho \varsigma \varsigma$ del Amor se manifiesta al comienzo de la pasión amorosa, atormentando al amante. Meleagro $(A P 7,419)$, por esta razón, también lo llamará $\gamma \lambda v \kappa v ́ \delta \alpha \kappa \rho v v ~ " E \rho \omega \tau \alpha$. Ovidio confesará que una puella es un dulce malum (Amores II 9, 26) ${ }^{12}$.

A medida que el amor penetra en el corazón de la víctima del flechazo, se manifiesta más y más claramente como un dolor, como un tormento, como

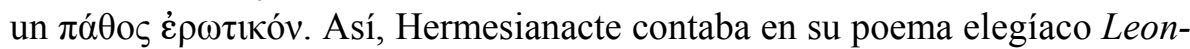
tion ( $C A$ 5) el terrible enamoramiento de Leucipo hacia su hermana por enojo de la diosa Afrodita; y para describir el sufrimiento que acarreaba dicho

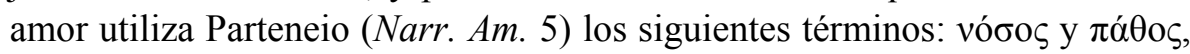

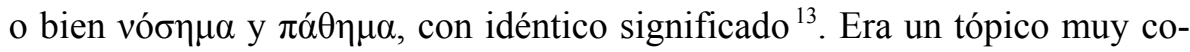
mún en la poesía helenística el que el amor se presente como una enfermedad (vóбos) que debilita a las personas que son víctimas de su embrujo ${ }^{14}$. Buena prueba de que los poetas alejandrinos consideraban el amor como una enfermedad contra la que no hay remedio, son los primeros versos del Idilio 11 de Teócrito ${ }^{15}$ :

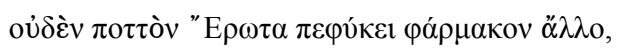

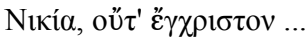

El amor se convierte en un fuego, un estado febril que prende de tal manera en el enamorado que éste sucumbe irremediablemente. Así lo presenta un fragmento elegíaco anónimo ( $S H$ 962) que debía de narrar una historia semejante a las de Pisídice, Nánide o Tarpeya - con abandono de sus debe-

12 Sobre este aspecto, cf. A. Carson, Eros the bittersweet. An Essay, Princeton 1986.

13 Parth., Narr. Am. 13.

14 cf. G. Giangrande, «Topoi ellenistici nell' Ars Amatoria», Cultura, poesia, ideologia nell' opera di Ovidio, (edd. I. Gallo-L. Nicastri) Nápoles, 1971, pp. 61-98 (en p. 80 s.).

15 Cf. G. Giangrande, "The Cure for Love in Theocritus' Idyll XI», ANMAL 13, 1990, pp. 5-9.

EMERITA. Revista de Lingüística y Filología Clásica (EM) - LXV 1, 1997, pp. 1-16 
res patrios por amor, como se verá más adelante -, y en el que se habla de un

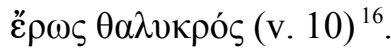

Otro tópico helenístico consistía en considerar el amor como una locura ( $\mu \alpha v^{\prime} \alpha$ ), es decir, un exceso irracional que acarrea grandes sufrimientos. El motivo de la $\varepsilon \rho \omega \mu \alpha v i ́ \alpha$ - término que hallamos especialmente en los epigramistas tardíos $(A P 5,220)$, Rufino $(A P 5,47)$ y Paulo Silenciario $(A P 5,255$; $256 ; 293)$ - está muy difundido en la época helenística y toma como punto

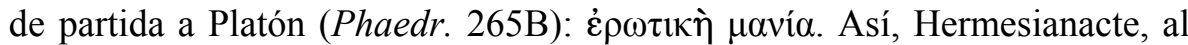
cantar que ni siquiera los filósofos - poseedores de $\mu \hat{\eta} \tau \iota \varsigma$ y $\dot{\alpha} \rho \varepsilon \tau \eta ́ ~(C A ~ 7,81$

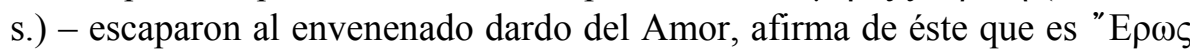
$\mu \alpha v$ ó $\mu \varepsilon v o \zeta(C A 7,83$ s.). Razón por la cual la pasión que Pitágoras sintió por su discípula Téano le produjo $\mu \alpha v i ́ n ~(C A 7,85)$. En definitiva, y por decirlo

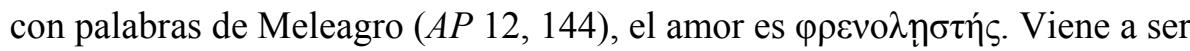
algo parecido a lo que expresa Apolonio de Rodas en un fragmento de su

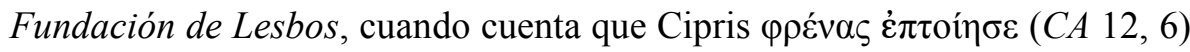
de Pisídice ${ }^{17}$, consiguiendo que ésta se enamorara de Aquiles - motivo de origen sáfico - También el $\pi \alpha \rho \alpha \kappa \lambda \alpha v \sigma i ́ \theta 0 \rho o v$ anónimo que nos ha transmitido el Fragmentum Grenfellianum (Lyr. Adesp., CA 1,32) dice que "E $\omega \omega \varsigma$

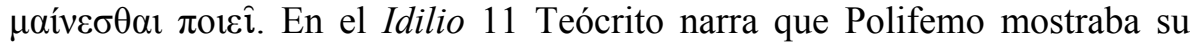

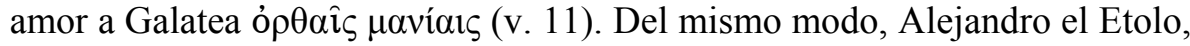
en su poema elegíaco Apolo, cuenta los apasionados amores de la esposa de Fobio hacia su joven huésped Anteo; aquélla se sentirá $\mu \alpha v$ ás $(C A 3,12)$ de amor hacia Anteo. Finalmente, Cleobea se suicidará sin ver cumplidos sus deseos eróticos ${ }^{18}$. En este fragmento, además, mediante la inuersio, es Cleobea quien con una hábil retórica logra que Anteo se introduzca en un pozo

16 Para Ovidio (Amores II 16, 11-12) su fuego --Corina-- está lejos (meus ignis abest), pero la ardiente pasión que suscita está cerca (ardor adest). El fuego es símbolo de la pasión amorosa: Tib. I 8, 7; II 4, 6; Prop. II 24, 8; III 9, 45 (cf. P. Pinotti, P. Ovidio Nasone: Remedia amoris, Bolonia, 1988, p. 82.

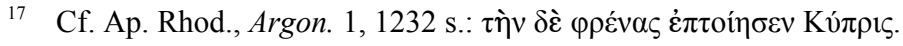

18 Se trata de un motivo que presenta una amplia incidencia en toda la literatura clásica, el llamado «Motivo de Putifar» (cf. J.M. Lucas, «El motivo de Putifar en la tragedia griega», Epos 8, 1992, pp. 37-56). La historia de Anteo y Cleobea, que parece que también fue el tema de una tragedia de Agatón (cf. C. Corbato, «L'Anteo di Agatone», Dioniso 11, 1948, pp. 163 -

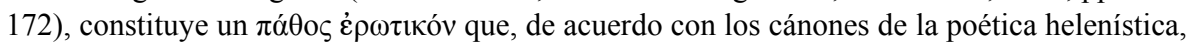
presenta un final desgraciado. Un estudio de este motivo se puede ver en J. Stern, «Alexander Aetolus, fragment 3», Eranos 85, 1987, pp. 35-39.

EMERITA. Revista de Lingüística y Filología Clásica (EM) - LXV 1, 1997, pp. 1-16 
para, así, satisfacer sus deseos de venganza por el amor no correspondido. El tópico ${ }^{19}$ erótico consistía en que el amante que deseaba lograr los favores de una muchacha debía tener, en primer lugar, una hablilidosa retórica. Así lo podemos ver, por ejemplo, en las Anacreónticas ( $f r .52$ Brioso) y en Apolonio de Rodas (Argon. 3, 458; 3, 1102; 4, 359), donde Jasón se muestra como un consumado orador para atraer a $\mathrm{Medea}^{20}$.

El tópico de la $\mu \alpha v i ́ \alpha$, de origen prehelenístico, gozó de mucha fortuna entre los poetas de este período y la elegía no escapó a él. Eurípides, por ejemplo, casi siempre concibe el amor como una $\mu \alpha v i ́ \alpha$ que acaba por entrar en colisión con el vó $\mathrm{o}_{\text {, }}$, las normas tradicionales de conducta, y que tiene dolorosas y nefastas consecuencias para el amante ${ }^{21}$. El elemento irracional del amor está ya perfectamente recogido en un fragmento de Anacreonte ( $f r$. 325 Page), en el que se ponen de relieve las locuras y disputas ${ }^{22}$ a que Eros conduce a sus víctimas:

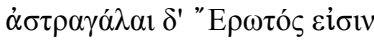

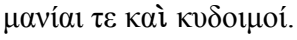

El dolor y la impotencia provocaban que en la elegía helenística la víctima de Eros llorase con asiduidad; esto era corriente en toda la poesía alejandrina. Contaba Filetas de Cos, en su Hermes, que Polimela ( $C A$ 5), cuyos amores con Odiseo se habían abortado por la repentina marcha de éste, estaba $\mu \varepsilon \tau \grave{\alpha} \pi \mathrm{o} \lambda \lambda \hat{\omega} v \delta \alpha \kappa \rho v ́ \omega v$. La poetisa Hédile de Atenas compuso una elegía titulada Escila, en la que narraba el amor de Glauco por Escila y el rechazo que experimentó por parte de ésta, historia que conocemos bien por las $\mathrm{Me}$ tamorfosis $(13,897-14,74)$ de Ovidio. En el fragmento que nos ha transmiti-

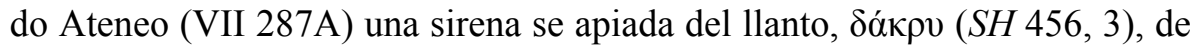
Glauco; fleuit amans Glaucus, dirá Ovidio (Met. 14, 68). Así pues, los sufrimientos que causa el amor tradicionalmente atormentan sin cesar a la perso-

19 cf. G. Giangrande, «Topoi ellenistici ...», art. cit., p. 67 s.

20 cf. G. Giangrande, «La concepción del amor en Apolonio Rodio», en La épica griega y su influencia en la literatura española, (ed. J.A. López Férez) Madrid, 1993, pp. 213-233 (en p. 231). El tema de la persuasión ha sido abordado también recientemente por F.R. Adrados, «Sobre las innovaciones de la poesía erótica griega», en Tradiziones e innovazione nella Cultura Greca de Omero all'Età Ellenistica, Roma, 1993, pp. 253-266.

${ }^{21}$ cf. F.R. Adrados, «El amor en Eurípides», en El descubrimiento del amor en Grecia, $2^{\mathrm{a}}$ ed., Madrid, 1985, pp. 177-200 (en p. 181).

22 cf. Ou., Amores I 7, 1-4 (las llamadas rixae in amore y los ataques de locura). 
na enamorada. Ni siquiera intentar dormir libra de los padecimientos ${ }^{23}$, ya que las preocupaciones torturan la mente, de suerte que en Fanocles ( $C A$ 1, 4 s.) el $\theta v \mu o ́ s$ de Orfeo, que estaba enamorado del bello Calais, no podía encontrar $\dot{\eta} \sigma v \chi \eta_{i}{ }^{24}$, y las $\mu \varepsilon \lambda \varepsilon \delta \hat{\omega} v \alpha u$ afligían la $\psi v \chi \eta \dot{~ d e ~ O r f e o, ~ q u e ~ n o ~ p o d i ́ a ~}$ dormir y estaba ö $\gamma \rho v \pi v o \varsigma^{25}$, todo ello a consecuencia de su $\pi$ ó $\theta$ o $\varsigma$ por Calais. Tampoco, cuenta Hermesianacte $(C A 7,64)$, escapó Eurípides a las

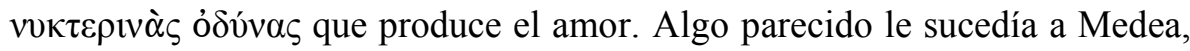
en Apolonio de Rodas (Argon. 3, 751 ss.), que no podía conciliar el sueño a causa de las $\mu \varepsilon \lambda \varepsilon \delta \eta ́ n \mu \alpha \tau \alpha$ que le proporcionaba su $\pi$ ó $\theta$ o hacia Jasón ${ }^{26}$. Los poetas elegíacos latinos también adoptaron este motivo helenístico ${ }^{27}$; para Tibulo (II 4, 11-12):

$$
\begin{aligned}
& \text { nunc et amara dies et noctis amarior umbra est: } \\
& \text { omnia nam tristi tempora felle madent. }
\end{aligned}
$$

En clara alusión al más amargo momento del día para el amante no correspondido: la noche. Se trata, pues, de un signum amoris típicamente helenístico.

Este deseo amoroso incontrolable se puede convertir en un fuego que atormente el corazón incluso de un dios, como le sucedió a Apolo, que estaba $\pi$ ó$\theta \omega$ каı́ $\mu \varepsilon v o \varsigma$ por Dafne, a la que perseguía denodadamente hasta que intervino la piedad de Zeus, que la metamorfoseó en el árbol del mismo nombre. Esta historia la contaba en sus elegías Diodoro de Elea ${ }^{28}$. Según Hermesianacte $(C A 7,37)$, también Mimnermo káícto Navvoûs. Esta es la razón de que Partenio llame al deseo que Clite sentía por Cícico $\dot{\alpha} \lambda \gamma \varepsilon v o ̀ v$ $\pi$ ó$\theta$ ov (Narr. Am. 27), en una historia que también contaban Euforión de

23 cf. Mel., $A P$ VII 195.

24 En Partenio (Narr. Am. 4) se dice que Alejandro está $\dot{\alpha} \theta v \mu \eta ́ \sigma \alpha \varsigma$ por la actitud de Enone.

25 Ovidio, en Amores I 2, 3, dice estar uacuus somno. cf. Tib. I 2, 75-78; Prop. II 22, 47.

26 Propercio (I 1, 33) habla de las noctes amaras; la misma expresión en IV 3, 29. cf. G. Giangrande, «La concepción del amor ...», art. cit., p. 220. El sueño es, en opinión de Meleagro ( $A P$ VII 196) el remedio contra los suplicios de Amor; el sueño (sopor) será para la Cintia de Propercio (I 3, 45-46) la ultima cura contra los sufrimientos que produce el amor.

27 Por ejemplo, Ou., Amores I 2, 1-8. cf. G. Giangrande, «Los tópicos helenísticos en la elegía latina», en Scripta Minora Alexandrina, II, Amsterdam, 1981, pp. 463-498 (en p. 482 S.).

28 Cf. Parth., Narr. Am. 15.

EMERITA. Revista de Lingüística y Filología Clásica (EM) - LXV 1, 1997, pp. 1-16 
Calcis, en su Apolodoro, y Apolonio de Rodas, en las Argonáuticas. Este $\pi$ ó$\theta$ o $\varsigma$ se torna insufrible, por más que Meleagro diga ingenuamente en una ocasión $(A P 12,101)$ que él era ö $\tau \rho \omega \pi$ ov $\pi$ ó $\theta$ ors.

En la poesía erótica griega era muy importante describir los padecimientos que produce el amor, padecimientos que duran siempre. En la elegía de

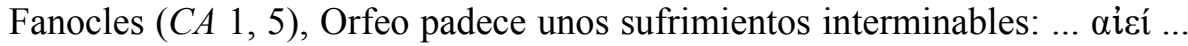
$\ddot{\alpha} \gamma \rho v \pi v o 1 . . . \mu \varepsilon \lambda \varepsilon \delta \hat{\omega} v \alpha$. Propercio (II 12, 13-16) lo expresa así:

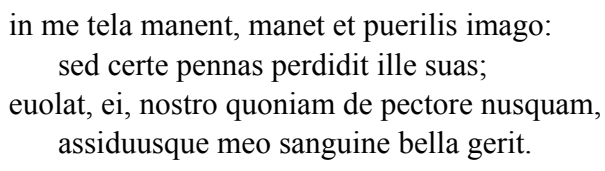

Las protagonistas de algunas elegías eróticas que menciona Partenio, como las de Pisídice (Narr. Am. 21) y Nánide (Narr. Am. 22), tienen un destino triste y trágico, por cuanto que el héroe amado se beneficiará de su amor y luego las abandonará a un cruel destino.

Como consecuencia de todo esto, el amante siempre se sentirá desgracia-

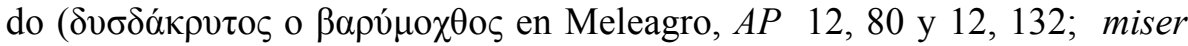
en Propercio I 1, 1, o en Ovidio, Amores I 1, 25; por no citar el conocido miser Catulle ... de Catulo 8, 1). En la elegía de Calímaco Aconcio y Cidipe, el primero sufre los rigores del amor y se confiesa $\lambda$ ıрò $\dot{\varepsilon} \gamma \omega ́$ ( $f r .74$ Pfeiffer),

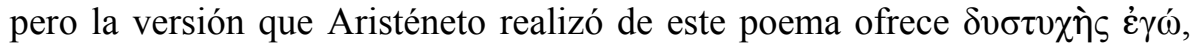
que encuentra eco en la versión ovidiana de las Heroidas $(20,135)$ : me miserum. Parece lógico que del amor contrariado se derive el tópico de la soledad, como la que experimentaban las mujeres tracias ${ }^{29}$ al ser rechazadas

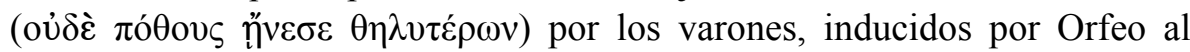

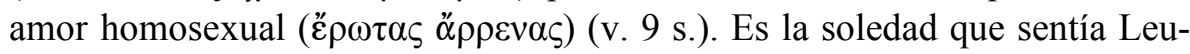
cone $^{30}$, la esposa de Cianipo, quien pasaba el día sola, ya que su marido llevaba una vida montaraz y de noche estaba tan cansado que, a veces sin mediar palabra, se sumía en un profundo sueño despreciando a su compañera de lecho. En definitiva, se trata también de uno de los tópicos más comunes en la poesía helenística: la necesidad de «corresponder al amor» ( $\dot{\alpha} v \tau \imath \varphi \imath \lambda \varepsilon i v)$. Esta necesidad - a veces trágica - la expresa muy bien Teócrito en el Idilio 6

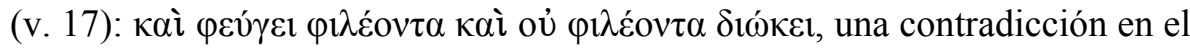

29 Phanocl., $C A 1$.

30 Parth., Narr. Am. 10. 


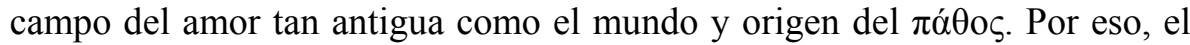
ideal del amor residirá, como en el caso de Propercio (I 1, 32), en su correspondencia:

sitis et in tuto semper amore pares.

No obstante lo dicho, según la tradición helenística, el momento apropiado para el amor es la noche ${ }^{31}$, y a ser posible a la luz del $\lambda v ́ \chi v o \varsigma$, que produce un ambiente de penumbra. Es lo que se desprende de un fragmento hexamétrico anónimo (SH 951) que narra cómo Hero y Leandro esperaban anhe-

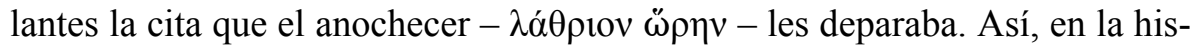
toria que cuenta Partenio sobre Periandro (Narr. Am. 18), la madre de éste se hallaba presa de incestuoso amor por su hijo. Para conseguir su propósito, concertó una cita mediante engaño con Periandro, bajo pretexto de facilitarle relaciones con una bellísima mujer; dicha cita sería de noche, y, para evitar ser reconocida, no debía encender las acostumbradas antorchas $(\lambda u ́ \chi v \alpha)$ por pudor. Sin embargo, Periandro, en una ocasión, sacó una antorcha y descubrió que se trataba de su madre. Periandro, tirano de Corinto y uno de los siete sabios de Grecia, desahogó su cólera provocando una matanza entre sus conciudadanos, mientras que su madre, cuyo nombre nos oculta la historia, se suicidó.

No es casualidad que, según cierta tradición ${ }^{32}$, se considere a Eros como

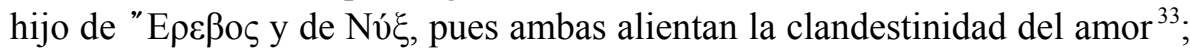
así al menos lo recoge uno de los poetas de la corte del macedonio Antígono II Gonatas, Antágoras de Rodas, quien en su Himno a Eros (CA 1, 3-4), dice como sigue:

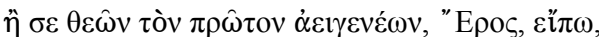

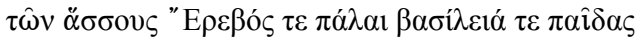

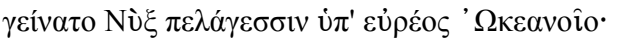

31 El enamorado desea alargar la duración de la noche cuando está en compañía de su amada. Este motivo se remonta a Homero (Od. 23, 241-246) y a Safo ( $f r .256$ Page) (cf. F. Martinazzoli, Sapphica et Vergiliana, Bari, 1958, p. 25 ss.) y aparecerá también en el epigrama helenístico (Mel., AP V 172). El Fragmentum Grenfellianum (Lyr. Adesp., CA 1, 11) llama a la Noche $\sigma v v \varepsilon \rho \hat{\omega} \sigma \alpha$.

32 cf. A. Ruiz de Elvira, Mitología Clásica, Madrid, $1982^{2}$, pp. 96-98.

33 Simias de Rodas ofrece una genealogía diferente, procedente de la cosmogonía órfica (cf. Hes., Theog. 116-120), según la cual Eros era hijo de Xáos (CA 24).

EMERITA. Revista de Lingüística y Filología Clásica (EM) - LXV 1, 1997, pp. 1-16 
La penumbra es, en efecto, la luz apropiada para el amor, como confirma la poesía experta de Ovidio (Amores I 5, 7-8) ${ }^{34}$ :

illa uerecundis lux est praebenda puellis, qua timidus latebras speret habere pudor.

La lucha interior suele ser un tópico frecuente en la poesía helenística: la persona enamorada intenta una resistencia al amor, pero éste resulta ser invencible. Tiempo después, el enamorado experimenta un cambio y pasa de la $\dot{\alpha} \mu \eta \chi \alpha v^{\prime} \alpha$ a la acción ${ }^{35}$. Esta $\mu \varepsilon \tau \alpha v o i ́ \alpha$ se explica mediante el tópico helenístico que reconoce a Eros como el $\delta ı \delta \alpha ́ \sigma \kappa \alpha \lambda o \varsigma$ por antonomasia ${ }^{36}$; así, Aconcio se abrasaba de deseo por la hermosa Cidipe y supo el camino a seguir

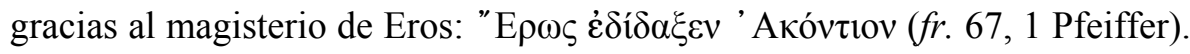
Eros enseña a amar y a seducir a la amada; por esta razón Propercio afirma que Eros donec me docuit castas odisse puellas (I 1,5), ya que el amor en la época helenística era concebido de una manera esencialmente carnal ${ }^{37}$. El

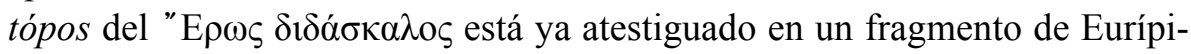
des ( $f r .430$ Nauck) y llega hasta la poesía de Nono de Panópolis, quien lo

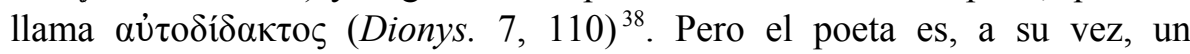

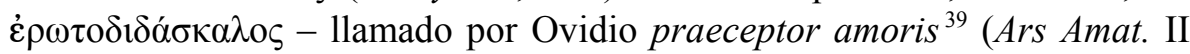
497) - que contempla en su programa el uso de la poesía para la conquista de la persona amada. Un buen ejemplo es la elegía de Hermesianacte, que ofrece un catálogo de las mujeres que fueron conquistadas por los poetas $(C A 7)$. En Hermesianacte se puede observar la tendencia helenística a considerar la poesía de Homero y de Hesíodo como carente de sentimientos, al tiempo que se esfuerza en presentar a estos dos poetas como poetas eróticos, cuya poesía amorosa había sido capaz de cautivar a sus amadas. Los poetas augústeos heredaron este programa poético ${ }^{40}$, según el cual la poesía erótica puede

34 Cf. Ou., Ars Amat. 2, 619-624; 3, 807-808.

35 cf. A. Buchholz, o. cit., p. 190.

36 cf. G. Giangrande, «La concepción del amor ...», art. cit., p. 222.

37 cf. El fragmento adespotum recogido en $\mathrm{SH} 961$.

38 También en las Anacreónticas encontramos un motivo semejante: Eros invita al poeta a acoger la posibilidad de amar: ع̈ $\pi \varepsilon \imath \theta^{\prime}$ "E

39 El motivo del praeceptor (o magister) amoris está también en Ou., Amores II 18, 20.

40 En Ovidio (Rem Am. 381-382), por ejemplo, se puede observar esta tendencia, según la cual ni la poesía de Calímaco, considerado como el maestro de la elegía (cf. G. Luck, La elegía erótica latina, Sevilla, 1993 [trad. esp.], p. 41), era apta para cantar las hazañas de 
conquistar el corazón de sus amadas, las doctae puellae ${ }^{41}$. En este sentido, Calímaco y Filetas eran considerados los maestros de la elegía erótica helenística, los principes elegiae, unos $\delta 1 \delta a ́ \sigma \kappa \alpha \lambda$ or en el campo del amor; leer sus elegías era contraproducente para quien quisiese librarse de caer en las redes de Eros, como previene Ovidio (Rem. Am. 759-760):

Callimachum fugito: non est inimicus Amori; et cum Callimacho tu quoque, Coe, noces.

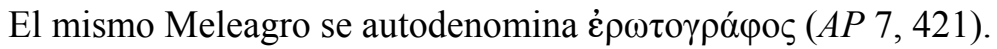

Otro tópico helenístico consiste en que las personas enamoradas faltan a sus deberes. Es lo que le sucedía a Nánide, hija del último rey lidio, Creso, la cual traicionó a su patria por convertirse en la esposa del invasor Ciro; sucedió después que Ciro no mantuvo sus promesas prematrimoniales una vez que consiguió conquistar Sardes. Así lo contaba Hermesianacte en el libro II de su poema Leontion $(C A 6)^{42}$. Una historia semejante es la que cuenta Partenio de Nicea (Narr. Am. 21), al transmitir lo sucedido a Pisídice, que por amor a Aquiles, entregó la ciudad de Metimna, bajo la promesa de contraer nupcias. Pero, como en el caso anterior, Aquiles no mantuvo su promesa y consintió que sus soldados lapidaran a quien había faltado a sus deberes patrios. Hay una interesante versión romana, deudora de las precedentes, que narra Símilo, poeta elegíaco del que nada se sabe, aunque probablemente haya que situarlo en el límite del período helenístico y dentro del círculo de Partenio de Nicea ${ }^{43}$. Se trata de una historia bien conocida a través de la poesía latina - la de Tarpeya, heroína epónima del Capitolio, enamorada del rey sabino Tacio -, de la que puede ser un ejemplo recomendable Propercio IV $4^{44}$. Ahora bien, Símilo, siguiendo las pautas de la poética helenística, pre-

Aquiles, ni los versos homéricos eran los adecuados para cantar a Cidipe, tal como hace el cireneo en su elegía Aconcio y Cidipe: Callimachi numeris non est dicendus Achilles, I Cydippe non est oris, Homere, tui.

${ }^{41}$ cf. G. Giangrande, «Textual and interpretative problems in Hermesianax», Scripta Minora Alexandrina, II, Amsterdam, 1981, pp. 387-410 (en p. 395 s.). El motivo del poeta praeceptor amoris es un motivo prehelenístico (cf. G. Giangrande, «Topoi ellenistici ...», art. cit., pp. 65-68, y J.G. Montes Cala, «Bión y la poética de Eros (a propósito del fr. 10 Gow)», Habis 25, 1994, pp. 87-90.

42 cf. Parth., Narr. Am. 22.

43 cf. E. Calderón, art. cit., p. 30.

44 cf. Ou., Fast. 1, 255-276; Met. 14, 772-777; Amores I 10, 47-50.

EMERITA. Revista de Lingüística y Filología Clásica (EM) - LXV 1, 1997, pp. 1-16 
senta una historia algo diferente, de la que son un buen testimonio los dos fragmentos transmitidos por Plutarco en su Vida de Rómulo $(17,6)(=S H$ 724). En su versión, Símilo narraba aspectos más novedosos de la leyenda; así, Tarpeya a quien entregó el Capitolio fue al rey de los celtas, del que se nos oculta el nombre, situando, pues, la aventura en la época de la invasión gala. El caso de Símilo podría ser un buen ejemplo de imitatio cum uariatione para acercar la leyenda a sus contemporáneos; asimismo, Partenio contaba alguna historia de amor que tenía lugar durante las correrías de los celtas (Narr. Am. 8). En cualquier caso, también en esta versión era aplastada Tarpeya por el peso de las armas galas, como castigo al deber faltado, pues

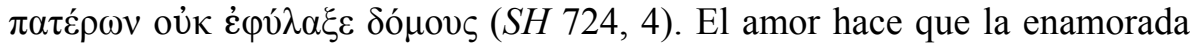
se mueva entre fuerzas contrapuestas: la razón, que le ordena ser fiel a los deberes patrios y paternos, y el amor, que le impele a entregar su voluntad al amado. Y el caso es que este tópico es típicamente femenino. Así, por ejemplo, sucede con Medea, que también traiciona a sus padres para ayudar a Jasón, del que está perdidamente enamorada, tal como lo describe Apolonio en las Argonáuticas (3, 630 ss.) ${ }^{45}$. Asimismo, Jasón también hace promesas de matrimonio a Medea (Argon. 4, 97) ${ }^{46}$. El autor anónimo de un fragmento elegíaco ( $S H$ 964) pone igualmente a Medea como ejemplo de mujer que ocasiona grandes males a ciudades y personas por estar bajo el yugo de Eros, un Eros que es calificado como $\dot{\alpha} \tau \alpha ́ \sigma \theta \alpha \lambda$ os (v. 19).

Un tópico fundamental en la poesía helenística es el de Eros invencible. El motivo del triunfo del Amor sobre el poeta enamorado es de origen helenístico y tendrá mucha fortuna a lo largo de toda la historia de la literatura posterior. Partenio, en una elegía titulada Crinágoras (fr. 11 Calderón), dedi-

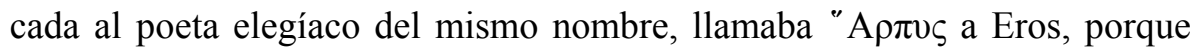
saltaba de improviso sobre los enamorados y los despojaba. Propercio plasma muy bien este tópico: et caput impositis pressit Amor pedibus (I 1, 4). Meleagro $(A P 12,101)$ dice que Eros es un dios tan poderoso que ha vencido incluso a Zeus. Ovidio hará la siguiente confesión (Amores I 2, 19): en ego, confiteor: tua sum noua praeda ... No tiene, por tanto, nada de particular que

45 cf. G. Giangrande, «La concepción del amor ...», art. cit., p. 225 s.

46 En Ovidio (Amores II 16, 43-46) es la palabra dada por una joven la que se lleva el viento (cf. Catull. 70; Prop. II 28, 8).

EMERITA. Revista de Lingüística y Filología Clásica (EM) - LXV 1, 1997, pp. 1-16 
los poetas alejandrinos dirijan vituperios contra Amor ${ }^{47}$. Imprudente actitud esta, como asevera un aforismo erótico helenístico $(C A 8 \mathrm{a})$ :

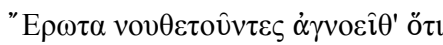

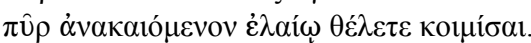

Hermesianacte $(C A 4)^{48}$ cuenta con ribetes novelescos la historia de $\mathrm{Ar}$ ceofonte, persona de fortuna pero de origen plebeyo, enamorado de Arsínoe, la malcriada hija de Nicocreonte, rey de los salaminios. Dicho enamoramien-

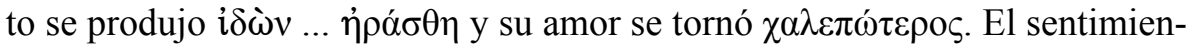
to de Arceofonte no era correspondido por la amada ni tolerado por su padre, por lo que decidió poner fin a sus días, ya que su amor había llegado a ser

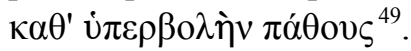

Junto a estos tópicos, la elegía helenística también se sirve de motivos que están recogidos en la literatura precedente. El más conocido tal vez sea el motivo del ह̌ $\rho \omega \varsigma \pi \alpha \imath \delta$ кós. Afirma Calímaco $(A P 12,150)$ que la pederas-

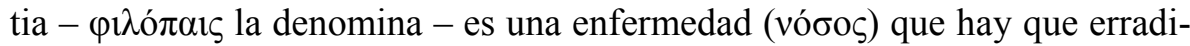

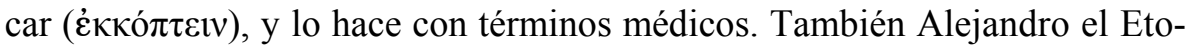
lo, en su elegía Las Musas, reconoce que este Eros produce locura $\pi \alpha 1 \delta o \mu \alpha v i ́ \alpha$ la llamará Plutarco (Mor. 769B) ${ }^{50}$-, ya que el poeta Agatocles había enloquecido ( $\pi \alpha 1 \delta o \mu \alpha v \varepsilon i ̂ v)$ por un joven $(C A 5,5)$. También Tibulo, necesitado de los placeres de un delicado joven llamado Márato, previene de

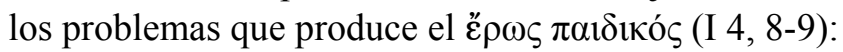

o fuge te renerae puerorum credere turbae, nam causam iusti semper amoris habent

También en la elegía Aconcio y Cidipe (fr. 68 Pfeiffer) destacaba Calímaco la admiración que el jovencito (кoûpos) Aconcio despertaba entre los varones cuando iba a la escuela o a los baños; hasta el punto de que se rifaban

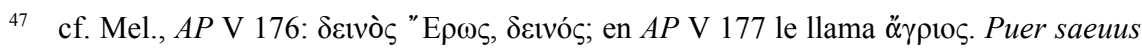
le llamará Ovidio (Amores I 1, 5). cf. Tib. I 6, 3; Prop. I 1, 6. El poder de Eros también está reflejado en los epigramas, cf. H. Kobus-Zalewska, «De Venere et Amore eorumque comitatu in Anthologiae Palatinae epigrammatis», Meander 45, 1990, pp. 159-175.

48 cf. Ant. Lib., Met. 39.

49 Hay una versión algo diferente en Ovidio (Met. 14, 698-764), en la cual Ifis totis perceperat ossibus aestum (v. 700) y había confesado a Anaxárete su miserum amorem (v. 703).

50 También en el epigramista Rufino encontramos $\pi \alpha 1 \delta o \mu \alpha v \eta ́ \varsigma(A P$ V 19).

EMERITA. Revista de Lingüística y Filología Clásica (EM) - LXV 1, 1997, pp. 1-16 


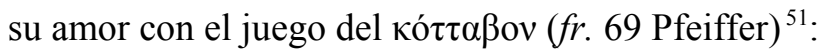

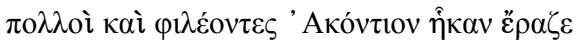
oivo

En este sentido, el testimonio mejor conocido es el de la elegía de Fanocles, de quien Plutarco dice que era un غ̇ que iluminan de manera indefectible el carácter de su poesía. Por Clemente de Alejandría (Strom. VI 2, 23) conocemos el título de su obra: "E $\mathrm{K} \alpha \lambda \mathrm{oi}^{52}$, si bien la segunda parte del título es un añadido para explicar la primera ${ }^{53}$. En esta elegía, contrapartida masculina del catálogo de amores célebres de Hermesianacte, Fanocles cantaba los amores homosexuales míticos bajo la forma de $\alpha i ̋ \imath \alpha$ - el género literario consagrado por Calímaco -, y

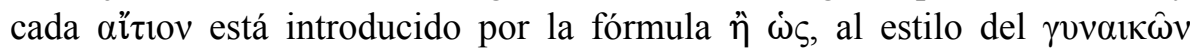

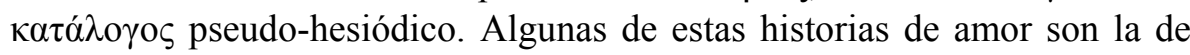
Dioniso, enamorado del bello efebo Adonis ( $C A 3)$, la de Tántalo, que raptó al joven Ganimedes ( $C A 4$ ), motivo de una guerra entre el padre de éste, Tros, y Tántalo, la de Agamenón, enamorado del joven Argino en Áulide, cuya muerte es el motivo etiológico que explica la fundación del templo de Afrodita Argínide, o la del rey ligur Cicno, enamorado de Faetonte ( $C A$ 6). Pero donde mejor se puede apreciar el motivo erótico en la elegía de Fanocles es en el alıtıov, conservado íntegro ( $C A 1)$, con el que el poeta quiere explicar por qué los tracios - todavía en su época - solían marcar a sus mujeres, y halla el origen de dicha costumbre en el mito de Orfeo enamorado del joven Calais y despedazado por las ménades tracias por haber enseñado, con su ejemplo, a los hombres a despreciar el amor de las mujeres y a preferir el

51 Consistía este juego - especialmente arraigado en Sicilia - en arrojar las últimas gotas de la copa a un recipiente situado en el centro. En caso de no acertar, se consideraba un mal augurio amoroso. En el caso que nos ocupa el fracaso es evidente, por cuanto que las gotas van a parar al suelo ( $f r .3$ West) (cf. C. Miralles, «La renovación de la elegía en la época clásica», BIEH 5, 1971, pp. 13-31, y últimamente del mismo autor, «Dionisio Calco: tradizione e innovazione nell' elegia del V secolo», en Tradiziones e innovazione ..., o. cit., pp. 501-512.

52 Como se ve, es el mismo título que la colección de elegías de Ovidio intitulada Amores, aunque el contenido no parece ser semejante. Sobre esta elegía puede verse: G. Morelli, «Fanocle», Maia 3, 1950, pp. 1-8, y L. Alfonsi, «Phanoclea», Hermes 81, 1953, pp. 379-383. El adjetivo kalóç parece ser un típico adjetivo de admiración homosexual (cf. N. Hopkinson, A Hellenistic Anthology, Cambridge, 1988, p. 178.

53 Lo atestigua Lactancio Plácido (In Ovid. Metam. 2, 367 ss.).

EMERITA. Revista de Lingüística y Filología Clásica (EM) - LXV 1, 1997, pp. 1-16 
de los jovencitos. El tatuaje era un signo que debía recordar a las mujeres el castigo que las antiguas culpables habían recibido de sus maridos después de haber dado muerte al mítico cantor. Al elegir una versión mítica que se aparta de otras más al uso, Fanocles nos revela su gusto exquisitamente helenístico, desdeñoso de todo lo que sea común. Era numerosa la lista de víctimas del ع́ $\rho \omega \varsigma \pi \alpha 1 \delta ı \kappa o ́ \varsigma$, cuyo poder fatal entraña la ruina para el hombre cazado en sus redes, incapaz de oponer resistencia y razón: غ̇ $\pi \imath v \mu \eta \hat{\sigma} \sigma \alpha \iota \mu \grave{\varepsilon} \nu ~ \ddot{\alpha} \pi \alpha \sigma \iota v$ $\dot{\alpha} v \theta \rho \omega ́ \pi 01 \varsigma$ ع̈ $v \varepsilon \sigma \tau \imath$, confesaba a Lisias $(3,4)$ un cliente para excusarse de haber intentado conseguir los favores de un muchacho.

De todo lo anteriormente expuesto se deduce que, a pesar de las dificultades que plantea estudiar un material tan escaso y fragmentario ${ }^{54}$, sí es posible apreciar que para estos poetas los sentimientos se mueven en una permanente tensión entre el amor y el desamor. El poema elegíaco helenístico tenía un contenido mítico erótico que generalmente acarreaba sufrimientos; es decir, દ̇ $\rho \omega \tau \iota \kappa \grave{\alpha} \pi \alpha \theta \eta \dot{\mu} \mu \alpha \tau \alpha$. En el fondo de la elegía se perfilaba como hilo conductor un asunto mítico o legendario con la inserción de todo tipo de digresiones y anécdotas extrañas, sobre todo aquellas que se encontraban en fuentes reducidas, a menudo de origen popular. De estas fuentes minoritarias se extraían los argumentos eróticos, con preferencia por el aspecto más barroco de las aventuras y amoríos extraviados de los héroes legendarios; aspecto este que, además, no había sido tratado por la gran poesía épica. Toda esta labor literaria se llevaba a cabo a través de tópicos perfectamente codificados por la poética helenística y prehelenística y que eran el vehículo ideal para cantar los amores doloridos del mito; tópicos muy precisos que se correspondían con los utilizados en otros géneros poéticos de este período y que eran la respuesta esperada a la concepción que el público helenístico tenía sobre el amor. Posteriormente, la elegía latina representará bajo esta especie de

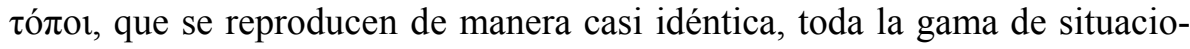
nes eróticas a las que el amor puede conducir y de las que, con frecuencia,

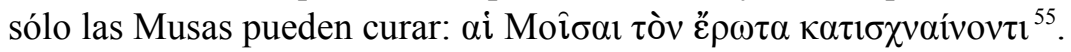

54 Sobre la cautela que exige tratar el tema del amor en la elegía de época helenística se puede ver lo dicho por M. Fernández-Galiano, «El amor helenístico», en El descubrimiento ..., o. cit., pp. 201-227 (en p. 224).

55 Call., AP XII 150. 
E. Calderón Dorda - Los tópicos eróticos en la elegía helenística.

ESTEBAN CALDERÓN DORDA

EMERITA. Revista de Lingüística y Filología Clásica (EM) - LXV 1, 1997, pp. 1-16 